\title{
SEX AND POWER IN INTERACTION: CONVERSATIONAL PRIVILEGES AND DUTIES*
}

\author{
Peter Kollock
}

\author{
Philip Blumstein \\ University of Washington
}

\author{
PePPer Schwartz
}

\begin{abstract}
This paper examines conversational behavior which previous research suggests is differentiated on the basis of sex. Interaction is conceptualized in terms of a sexual division of labor wherein men dominate conversation and women behave in a supportive manner. The literature raises the question of whether these differences in conversational patterns are tied to power as well as sex. A study was designed to determine which of a set of variables reflecting conversational duties and privileges are linked to power, to sex, or to both. The data were coded from interactions of intimate couples divided among those with both partners sharing power equally and those where one partner has more power. Three types of couples were compared: cross-sex couples, male couples, and female couples. Interruptions and back channels are linked to power regardless of the sex of the actor, as are tag questions, although the rarity of their occurrence makes any conclusions tentative. The more powerful person interrupts his or her partner more and produces lower rates of back channels and tag questions. Talking time and question asking seemed linked to both sex and power, though not in any simple way. The results of the analyses of minimal responses and overlaps proved inconclusive.
\end{abstract}

In recent years there has been a growing research interest in. sex differences in speech (e.g., Thorne and Henley, 1975; Thorne et al., 1983). Conversational behavior, it was once argued, can be viewed as having a "male dialect" and a "female dialect" (Kramer, 1974). More recent commentators feel that such a conceptualization exaggerates and at the same time oversimplifies the differences between men's and women's speech (Thorne et al., 1983:14). However, neither these authors, nor any others, deny that there are significant sex differences in verbal interaction.

As various sex differences were observed, some authors began to look at possible reasons for their existence and at their implications. Notably, some researchers (cf. Fishman, 1978;

*Direct all correspondence to: Peter Kollock, Philip Blumstein, and Pepper Schwartz, Department of Sociology, DK-40, University of Washington, Seattle, WA 98195.

This research was supported in part by NSF grant SES-7617497 and a research assistantship to the first author from the Graduate School of the University of Washington. A draft of this paper was presented at the Annual Meeting of the American Sociological Association, San Antonio, 1984.

The authors are grateful to these colleagues for comments on an earlier draft of this paper: Nancy Durbin, Mary Rogers Gillmore, Laurie Russell Hatch, Judith A. Howard, Mary Savage Leber, Anne Martin, Barbara Risman, Donald Stull and Toshio Yamagishi. We would also like to thank Sandra Hayashi for her work in coding the conversations.
Thorne and Henley, 1975) felt that these differences were tied not solely to sex, but to power as well. In looking, for example, at differences in the amount of time spent talking, at terms of address, and at interruption patterns, the implication was that observed sex differences in language mirror the overall difference in power between men and women, and that the way in which people communicate reflects and reinforces the hierarchical relationships that exist around them.

As intriguing or intuitively appealing as these questions may be, there have been few studies to test empirically what relationship power and sex have to the observed differences in men's and women's speech.

\section{A MODEL OF TURN TAKING IN CONVERSATION}

Our analysis of conversation is based on a model of turn taking derived from the work of Sacks et al. (1974) and of Zimmerman and West (1975) on the organization of verbal interaction. Conversation is organized to insure that one speaker talks at a time and that change of speakers occurs. A speaker's turn should not be thought of merely as the segments of time he or she speaks. Rather it is a concrete as well as symbolic platform on which an actor may accomplish his or her interactional goals and may also block the other person from effectively delivering a message. Speaking turns can have attached to them responsibilities, obligations, or privileges. Consequently, they 
may not be equally distributed and are often fought for. Much of the time the transition between turns occurs smoothly with little or no gap or overlap in the conversation. In order to accomplish this, a listener must anticipate when the end of a sentence will occur or infer when the speaker has finished a thought. The implication, then, is that each person must work and continuously analyze the conversation in order to keep it going smoothly. Conversation involves both active "speakership" and active "listenership," the roles being continuously exchanged (Zimmerman and West 1975:108).

This model is more than an abstract representation of how conversation works. It also reflects the normative ordering of talk: these are the rules of turn taking, and speakers are constrained to respect and obey them-at least in their broadest strokes-or risk sanctions. It is important to recognize that there are implicit rules that govern " polite" or "proper" conversation and that a certain amount of work must necessarily be done by the participants if the interaction is to go smoothly. In looking at a conversation we may then ask which persons are respecting these implicit rules and which persons are violating or ignoring them. The rules of turn taking may not apply equally to all classes of actors. In most every society sex is a basis for allocating tasks, responsibilities, duties and privileges, and the empirical literature suggests that such a division between men and women exists in terms of duties and privileges in conversation (cf. Fishman, 1978).

\section{CONVERSATIONAL DIVISION OF LABOR}

There are two major elements to the division of labor within verbal interaction: conversational dominance and conversational support. A conversation can be dominated by using a disproportionate amount of the available time as well as through the use of interruptions which serve to gain the floor. In addition, interruptions can be a sign of disregard toward the rules and etiquette of polite exchange as well as a projection on the speaker's part that he or she is worthy of more attention-has more of value to say and less to learn-than the other party.

With regard to the amount of time spent talking, the stereotype-as expressed in such folk expressions as the Scots' "Nothing is so unnatural as a talkative man or a quiet woman" (cited in Swacker, 1975)-is that women are more loquacious. A large body of research, however, indicates that men talk more than women do (Argyle et al., 1968; Bernard, 1972; Hilpert et al., 1975; Kester, cited in Kramer, 1974; Marlatt, 1970; Rosenfeld, 1966; Soskin and John, 1963; Strodtbeck, 1951; Swacker, 1975).

Research on interruptions has generally shown that men interrupt women much more often than women interrupt men (Argyle et al., 1968; Eakins and Eakins, 1978; Kester, in Kramer; 1974; Natale et al., 1979; Octigan and Niederman, 1979; Zimmerman and West, 1975). Zimmerman and West felt that the differences among cross-sex dyads were reflections of the power and dominance enjoyed by men in society, and in a subsequent study (West and Zimmerman, 1977) found the same sort of marked asymmetry in rates of interruptions among adult-child dyads, thereby giving further credence to the idea that the differences were tied to status. The notion that interruptions are a form of dominance is also supported in the work of Courtright et al. (1979), Eakins and Eakins (1978), Rogers and Jones (1975), and West (1984).

The work of Sacks et al. (1974) on turn taking makes clear that some sort of work is necessary to insure smooth transitions between turns. Fishman (1978:399) expands on the idea of "interactional work":

In a sense, every remark or turn at speaking should be seen as an attempt to interact. Some attempts succeed; others fail. For an attempt to succeed, the other party must be willing to do further interactional work. That other person has the power to turn an attempt into a conversation or to stop it dead.

In the literature on behaviors which help to keep the conversation going and which may serve to support the speaker, three types of speech element are central. These are the use of (1) questions, (2) tag questions, and (3) minimal responses. In her study of interactional work, Fishman (1978) found that women asked two and a half times as many questions as men. Questions, like greetings, evoke further conversation in that they require a response. The asking of questions supports the conversation by insuring minimal interaction. Fishman also found differences in the use of minimal responses. By a minimal response is meant such simple one- or two-word responses as "yeah," "uh huh," or "umm." Schegloff (1972) points out that one speaker will often intersperse minimal responses within another speaker's turn, not as a way of interrupting or invading the other's turn, but rather as a way of displaying interest and support for what the other person is saying. Minimal responses, however, can be used in various ways.

Fishman argues that males use them as lazy ways of filling a turn and as a way of showing a lack of interest (the woman may make a long statement touching on a variety of issues to 
which the man simply replies "uh-huh"). Among women, however, Fishman found that their most frequent use was as described by Schegloff: minimal responses were skillfully interspersed within the male's turn as a form of passive support. The insertion of these minimal responses in the other person's turn (sometimes called back channels) was usually done with great skill, making use of the slight gaps or pauses for breath that occurred, so as not to affect the flow of the other person's speech or interrupt the other in any way. Such timing demonstrates that the woman is paying very close attention to her partner's speech.

Lakoff (1975) also asserts that women ask more questions than men, and she additionally believes that they use tag questions much more often than men. A tag question is a hybrid between a question and an outright statement (e.g., "It's cold in here, isn't it?"), and can be a way of avoiding making strong statements. It does not force agreement with one's beliefs; it asks, rather, for confirmation of those beliefs. The use of tag questions implies the person somehow has less right to voice his or her opinions and less right to make a simple assertion in order to define the situation. They can also be used, much in the same manner as questions, as a way of encouraging conversation. In empirical investigations, Fishman (1980) and Eakins and Eakins (1978) found that women used tag questions more often than men. Other researchers, however, have found that tag questions were used more by men than by women (e.g., Dubois and Crouch, 1975; Lapadat and Seesahai, 1977).

\section{LOGIC OF THE STUDY}

In general, then, the literature suggests that men talk more, interrupt and overlap others more, and use minimal responses as a lazy way of filling a turn and showing a lack of interest. Women, on the other hand, seem to talk less, interrupt less, ask a greater number of questions and tag questions, and use minimal responses (back channels) as a way of supporting the other speaker. We see, then, a division of labor in which women nurture the conversation by working to keep it going and by obeying the rules implicit in polite interaction in order to make the transition and allocation of turns go smoothly, while men freely violate these rules without repercussions and further dominate the conversation by using a disproportionate amount of the time.

Previous research on the sexual division of labor in conversation has generally confounded the effects of sex and power. For us the question becomes: Are the interactional privileges and duties linked to power, to sex, or to both?
Kramer (1974:20) notes that "it would be interesting to see if female speech patterns once found in a variety of situations in which women are in the subordinate position are found in situations where a woman speaks from some base of power." One would, of course, also want to look at such situations as two men in which one was more powerful and one was less, or a cross-sex dyad in which the woman was higher and the man was lower. In other words, we want to find a research setting in which sex and power can vary independently. This suggests a two-dimensional design with sex composition of the dyad being one dimension $(F-F$ versus $M-F$ versus $M-M)$, and power within the dyad being the second dimension (both speakers being equal versus power imbalanced). A critical ingredient in the design would be the inclusion of cross-sex dyads in which the woman is the more powerful partner, as well as the more usual case where she is the less powerful.

\section{METHOD}

The cases to be used for this investigation are a subsample of a larger study on role differentiation (see Blumstein and Schwartz, 1983). The larger study compares the nature of interpersonal relations in four types of couples who live together-heterosexual married couples, heterosexual unmarried cohabitors, male homosexual couples, and lesbian couples. The study was conceived to use the same-sex couples as naturally occurring comparison groups in order to examine the ways in which role differentiation based on sex affects couples.

It might be argued that male and female homosexuals are not a relevant comparison to heterosexual married and cohabiting couples. Perhaps it is true that two factors, at least-the effects of living a stigmatized life and the putative socialization antecedents in the development of a homosexual identity-have created homosexual men and women who are very different from heterosexuals and who therefore cannot provide generalizable insights into male and female sex roles. However, both our own research (Blumstein and Schwartz, 1983) and other recent studies on male and female homosexuality have emphasized the continuities of behavior and attitudes within sexes and across sexual-orientation categories (Bell et al., 1981; Gagnon and Simon, 1973; Symons, 1979). These continuities reflect the potency of the norms governing the acquisition and maintenance of sex roles.

Ultimately, the comparability of heterosexuals with homosexual men and women is not critical to the argument of this paper. In same- 
sex couples, sex is not a marker of internal differentiation around which to organize variations in conversational behavior. If power differentials in these same-sex pairs are observed to covary with conversational support and dominance, then it is reasonable to rule out sex as the sole source of the division of labor. in interaction. Attention can then be turned to the broader question of how structural properties of groups affect conversation.

All of the couples in the study were living together in intimate relationships. This provides a response to a criticism sometimes leveled at research on conversation, that the data come from "unnatural" sources. For example, Hirshman (cited in Thorne and Henley, 1975:248), in a study which generated inconclusive results, argued that the awkwardness of the setting in which the subjects found themselves (two males and two females, all previously unacquainted, interacting in a laboratory setting) led to conversation that was strained, generally very polite, and somewhat unnatural. Parks (1978) voiced a similar concern when he questioned the validity of research that has employed zero-history, ad hoc experimental groups. These critics imply that it would be desirable, in choosing dyads for study, to use couples who are involved in ongoing relationships and to record their conversations in a natural and familiar setting.

The present research involved a detailed questionnaire, a version of which was completed independently by each partner in the couple, and which dealt with a large number of topics concerning the division of labor within the relationship, power and influence, satisfaction, etc. (see Blumstein and Schwartz, 1983:603-43). ${ }^{1}$ The questionnaire was also used to provide stratification criteria for selecting a subsample of couples to be interviewed in depth in their homes.

The interview sample was drawn largely from three different locales within a one-hour driving radius of Seattle, San Francisco, or New York). ${ }^{2}$ The questionnaire subsamples

\footnotetext{
${ }^{1}$ The total numbers of couples with usable data (two completed questionnaires in each) are: 4,314 heterosexual couples (of whom approximately 85 percent were married), 969 male homosexual couples, and 788 lesbian couples. These figures reflect return rates of 58 percent, 52 percent, and 46 percent, respectively.

${ }^{2}$ In finding the original questionnaire respondents, the investigators attempted to secure a large and diverse group, at the same time acknowledging the unique problems that finding male homosexuals and lesbians-and to a lesser degree, heterosexual cohabitors-posed (see the discussions of sampling stigmatized persons in, e.g., Bell, 1974; Weinberg, 1970). Couples were sought for participation through
}

fitting these geographical constraints were stratified on two variables: duration of the relationship (3 levels); and socioeconomic status (3 levels), as measured by educational data on each partner. ${ }^{3}$ It was also attempted informally to maximize the diversity of several other criteria within each stratum (i.e., age, number of prior relationships, presence of children, etc.). Within each duration by class level cell, couples were chosen at random, with approximately 100 couples of each of three types (F-F, M-F, M-M) ultimately selected to be interviewed. ${ }^{4}$

The interviews were generally carried out by male/female teams in the homes of the subjects and were designed to probe the nature, history, and day-to-day functioning of the relationship. In part of the interview the couple was given several conflict situations to resolve (modifications of role scenes suggested by Raush et al., 1974). Each person in the couple read five short stories dealing with such problems as a member of a couple refusing to go to a party or spending a large amount of time on a hobby. The two people read slightly differently slanted versions of the same basic stories. The essen-

a number of different methods, including the usè of local and national print and broadcast media, soliciting in public gatherings (e.g., PTA meetings, churches and synagogues, union gatherings, gay and lesbian social and political organizations, etc.), and canvasing neighborhoods with high densities of the kinds of couples desired. This recruitment plan, devised to find large numbers of same-sex couples, was also applied to heterosexual couples, in order to maintain comparability of recruitment effort. National representativeness of the male homosexuals, lesbians, and cohabitors was believed impossible to achieve, and so diversity and large numbers were made the goal. By keeping the recruitment procedures comparable for all four kinds of couples, the possibility of representativeness among the married couples was lost. In general, the couples who returned questionnaires tend to be better educated and more predominantly white than the nation as a whole. (See Blumstein and Schwartz, 1983:16-19 for a description of the recruitment process and 593-602 for a statistical profile of the couples.)

${ }^{3}$ Couples of short duration were defined as those living together less than two years, while those of medium duration were together between two and ten years, and those over 'ten years were classified as being of long duration. Low-education couples were defined as neither partner having gone beyond high school. Medium-education couples were those where at least one partner had attended college, and high-education couples were those where at least one partner had a degree higher than a B.A.

4 The plan was to interview 300 couples, but due to the vagaries of scheduling, a larger number was actually interviewed: 129 heterosexual couples (approximately 40 percent unmarried cohabitors), 93 lesbian couples, and 98 male homosexual couples. 
tial facts were the same, but the points of view varied regarding which of the actors was more in the wrong. As each person read the stories he or she was asked to mark on a separate sheet which character he or she felt was more justified. The couple was then brought together with their answer sheets (but without the stories) and were asked as a couple to decide which character in each story was more justified and what would be the best means of resolving the conflict. This conversation between the couple occurred in the absence of the interviewers and was tape recorded. The data presented below are derived from the recordings of these conversations.

From this population of interviewed couples a subsample was selected on the basis of the power dynamics in the relationship in order to fill the two-dimensional design discussed above.

Power was operationalized by constructing a scale composed of eight items from the original questionnaire. The items were selected from a group of questions which asked who in the relationship had more influence with regards to particular decisions concerning their day-to-day life (i.e., where to go on vacation, when to go out to eat, etc.). ${ }^{5}$

Based on the power scale, all of the interviewed couples were categorized as either power-balanced or power-imbalanced and the cross-sex imbalanced couples were further subdivided into couples in which the male has greater power and couples in which the female is the more powerful member. From each category, five couples were chosen to fill the cells in the design, for a total $\mathrm{N}$ of 35 couples. In the

\footnotetext{
5 Factor analyses, performed separately for heterosexual males, heterosexual females, homosexual males, and lesbians, yielded eight relative influence items with reasonable internal consistency over the four groups. The answers to these questions were summed together to form a simple additive scale. The scale has the following alpha reliability coefficients in the entire questionnaire samples: heterosexual males: .601; heterosexual females: .649; homosexual males: .650; and lesbians: .570. The decision areas represented in the eight items are: whether to move residence; where to go on vacation; when to go out to eat; how much money to spend on home furnishings; how much money to spend on entertainment; how much money to spend on groceries; whom to invite to the couple's home; and where to go out for an evening (the exact wording of items appears in Blumstein and Schwartz, 1983:612-13). There was high agreement within the subsample between partners with respect to the overall power measure, the intracouple correlations being: cross-sex couples, $r=-.939$; male couples, $r=-.813$; female couples, $r=-.994$ (because of the item wording, a negative correlation reflects agreement).
}

case of the power-imbalanced couples the two members had to agree as to who had more influence and who had less.

\section{ANALYSIS OF THE CONVERSATION}

Based on the literature and the previous discussion, data were gathered from each conversation on the following items for each person:

1. Total number of seconds spent talking.

2. Number of overlaps. It is important to distinguish between overlaps and interruptions. Using Zimmerman and West's criteria (1975), overlaps are those instances of simultaneous speech which occur at or very close to a legitimate transition place or ending point in the present speaker's turn, for example: ${ }^{6}$

Female 73372: . . . there would have been no half-hour lateness, and there would have been no pro[ $\mathrm{blem}$. $]$

Male 73371: on't figure a half hour is worth arguing over.

In contrast, interruptions are a deeper intrusion into the current speaker's turn.

3. Number of interruptions (and whether or not they were successful). In a successful interruption, the first speaker stops talking (cedes control of the floor), allowing the second speaker to communicate a complete message. For example:

Female 73372 : If he went to a party with
Male 73371: what the question said.

An unsuccessful interruption occurs when the first speaker refuses to cede control of the floor and continues to talk in order to complete his or her message despite the attempt of the second speaker to interrupt. For instance:

Male 10441: If you're late on purpose, or

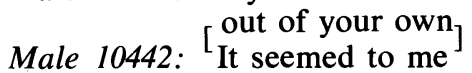

Male 10441: neglect, then that's one answer.

4. Number of minimal responses used as a turn. These are generally simple one- or twoword responses, argued by Fishman (1978) to be a lazy means used to fulfill the requirement of a spoken turn. For example:
Male 10442: I think Carl should have the right to talk to somebody else about a relationship.

${ }^{6}$ Brackets used in quoted speech indicate that the enclosed material occurred simultaneously. 
Male 10441:

Male 10442:

Mm hmm.

Espe-

cially if it's in a way of trying to understand it.

5. Number of back channels. Superficially, back channels resemble minimal responses used as a turn. Both are the "uh-huh's" which punctuate conversation. But unlike the latter, which denote laziness on the speaker's part, the use of back channels serves as a sign of the listener's encouragement and support. The capacity to intersperse interested feedback into the uninterrupted flow of the other's speech reflects both conversational skill and a willingness to engage in "interactive work." For instance:

Male 10172: I think Larry is more justified. It [ sounded like

Male 10172: really several nights a week Male 10171: ${ }_{\text {Sure }}^{\text {and }}$ ] ${ }^{\text {a weekend. }}$

6. Number of questions.

7. Number of tag questions:

Male 10171: On the first one, $\mathrm{I}$ think $\mathrm{Al}$ is justified about Bill's lateness, don't you?

Simply looking at the number of questions or interruptions that someone utters would be misleading; a person may ask a greater number of questions than his or her partner simply because he or she talked for a greater amount of time. The variables have therefore been adjusted so as to control for a speaker's talking time. The number of questions asked, for example, is divided by the person's talking time in seconds and multiplied by 900 , yielding a figure indicating the number of questions asked per quarter hour. What are examined in this study, therefore, are rates of interruptions, overlaps, questions, tag questions, minimal responses and back channels. ${ }^{7}$

${ }^{7}$ A subset of the conversations (25 out of 35 ) were analyzed a second time by a second coder in order to estimate intercoder reliabilities for each of the dependent variables. The intercoder correlations are as follows: talking time, $\mathrm{r}=.989$; successful interruptions, $\mathrm{r}=.753$; unsuccessful interruptions, $\mathrm{r}=.872$; overlaps, $r=.698$; minimal responses, $r=.737$; back channels: $r=.752$; questions, $r=.925$; tag questions, $r=.586$. The last reliability is relatively low, probably due to the infrequency of the behavior. Consequently, findings for this variable should be interpreted with caution.

\section{DATA ANALYSIS}

Since the behavior of an individual within a couple is not independent of his or her partner's behavior, the couple must be treated as the unit of analysis. This fact, combined with the fact that the study does not involve a balanced factorial design, suggests several strategies for analysis. While none is, in itself, a perfect solution, they are used together with the belief that collectively they converge on an optimal, yet conservative way of approaching the hypothesis-testing problem. ${ }^{8}$

Three different types of analysis of variance were performed. The first (Type 1) involves a 3 by 2 design, with sex composition being one dimension $(M-M, M-F, F-F)$ and power balance within the couple being the second dimension (equal versus unequal). Type 1 analyses treat as dependent variables the means of the two individuals within each couple for each element of conversation. For example, a Type 1 analysis can compare equal with unequal couples in the number of interruptions within the conversation, or it can compare the three different sex compositions in terms of overall loquaciousness. It should be noted that for Type 1 analyses, in the powerimbalanced cross-sex couples' the distinction is obscured as to whether it is the male or the female who has the greater power. Consequently, while these analyses may show, for example, whether cross-sex couples display very high rates of asking questions, they cannot tell whether it is the more powerful or less powerful partner (or alternately, male or female) who is asking the greater number of questions. This problem leads to two other kinds of analysis.

Type 2 and Type 3 analyses involve repeated-measures designs using the couple as the unit of analysis, but where each partner within the couple is viewed as a unit of observation. These analyses only make sense when looking at couples which are in some way internally differentiated, be it by sex (male versus female) or by power (more versus less powerful). Type 2 analyses look at the effects of sex within the couple, making use of the cross-sex couples only. The couples were classified into three possible types (powerbalanced; imbalanced, with the male more powerful; and imbalanced, with the female more powerful), yielding a 3 by 2 design with sex (male versus female) as the repeated measure.Type 2 analyses allow one to look at the effects among the cross-sex couples of power balance/imbalance, sex, and the position one

${ }^{8}$ The authors wish to thank Charles T. Hill for suggesting the analysis strategy. 
holds in an unequal relationship. One can see, for example, how couples in which the female has greater power than the male differ from couples in which the reverse is true.

The final analyses (Type 3) look at the effects of a person's position of power in the relationship and thus deal only with the powerimbalanced couples, yielding a 3 by 2 design examining male couples, female couples, and cross-sex couples and using a person's position of power (more powerful versus less powerful) as the repeated measure. ${ }^{9}$

\section{RESULTS \\ Talking Time}

Is loquaciousness associated with sex or with power or both? The pattern in the data is not totally consistent, but there is some evidence that talking time is greater for men and for the more powerful partner. A Type 2 analysis of variance yields a near significant main effect for $\operatorname{sex}(F(1,12)=3.2 ; p<.10)$. The sex difference varies depending on the power dynamics of the couple. Looking first at the traditional pattern (where the man is more powerful), we find that men do speak substantially more than women (see Table 1).

However, in the power-balanced couples, there is no appreciable difference in loquaciousness between men and women. Before we hypothesize that it is power rather than sex which accounts for the apparent sex difference in the couples where the man is more powerful, we should note the very large sex difference among the "role-reversed" couples (female more powerful). While the females in these couples are more talkative than their counterparts in traditional couples, their male partners are more talkative than anyone else in the study.

The striking tendency of these lower-power males to talk a great deal does not generalize to the male couples. For them, the more powerful partner is somewhat more loquacious than the less powerful (mean talking times of 245 versus 210 seconds). Indeed these couples cast serious doubt on the notion of males being generally more talkative, since among powerimbalanced couples, male couples have lower rates than female or cross-sex couples (mean for male couples: 228 seconds; female couples: 300 seconds; cross-sex couples: 389 seconds).

The female couples illustrate that pure power dynamics can affect loquaciousness.

\footnotetext{
${ }^{9}$ It should be noted that while the Type 1 analyses aggregate the data within each couple, Type 2 and 3 analyses allow for disaggregation of the data while still keeping the couple as the unit of analysis.
}

Table 1. Mean Talking Time in Seconds (CrossSex Couples) ${ }^{\mathrm{a}}$

\begin{tabular}{lccc}
\hline \hline & Males & Females & $\begin{array}{c}\text { Group } \\
\text { Mean }\end{array}$ \\
\hline $\begin{array}{l}\text { Balanced couples } \\
\begin{array}{l}\text { Couples with male } \\
\text { more powerful }\end{array}\end{array}$ & 292 & 286 & 289 \\
$\begin{array}{l}\text { Couples with female } \\
\text { more powerful }\end{array}$ & 385 & 330 & 358 \\
$\quad$ Group Mean & 385 & 373 & 419 \\
\hline
\end{tabular}

${ }^{\text {a }} \mathrm{N}=5$ people per cell.

The more powerful partner talks more (mean of 333 seconds) than the less powerful (mean of 267). The talking time of power-balanced female couples falls in between (mean of 304 seconds).

\section{Interruptions and Overlaps}

The number of interruptions is clearly tied to power in cross-sex couples. The means in Table 2 reflect a significant sex by powercomposition interaction effect $(F(2,12)=6.6$; $\mathrm{p}<.01)$. There is no sex difference in the powerbalanced couples, but partners greater in power-male or female-interrupt a great deal more than weaker partners. Interruptions are clearly a sign of conversational dominance. However, not all interruptions are successful (fewer than 50 percent in our data). In other words, in more than half the observed cases, the interrupted party did not yield the floor. Perhaps, then, it is better to think of interruptions as attempts at conversational control. Successful interruptions, then, become a more sensitive measure of actual dominance. A Type 2 analysis of variance on rates of successful interruptions yielded a pattern of means very similar to those in Table 2 (interaction effect $F(2,12)=8.3 ; p<.01)$.

The question remains as to whether the relationship between power and successful interruptions occurs solely in cross-sex couples. Table 3 shows that same-sex couples experi-

Table 2. Mean Number of Interruptions per Quarter Hour (Cross-Sex Couples) ${ }^{a}$

\begin{tabular}{lccc}
\hline \hline & Males & Females & $\begin{array}{c}\text { Group } \\
\text { Mean }\end{array}$ \\
\hline $\begin{array}{l}\text { Balanced couples } \\
\begin{array}{l}\text { Couples with male } \\
\text { more powerful }\end{array}\end{array}$ & 17.6 & 17.4 & 17.5 \\
$\begin{array}{c}\text { Couples with female } \\
\text { more powerful }\end{array}$ & 23.5 & 13.6 & 18.5 \\
Group Mean & 14.7 & 24.7 & 19.7 \\
\hline
\end{tabular}

${ }^{\text {a }} \mathrm{N}=5$ people per cell. 
Table 3. Mean Number of Successful Interruptions per Quarter Hour (Power-Imbalanced Couples)

\begin{tabular}{lccc}
\hline & $\begin{array}{c}\text { More } \\
\text { Powerful } \\
\text { Partner }\end{array}$ & $\begin{array}{c}\text { Less } \\
\text { Powerful } \\
\text { Partner }\end{array}$ & $\begin{array}{c}\text { Group } \\
\text { Mean }\end{array}$ \\
\hline Male couples & 5.7 & 3.1 & 4.4 \\
& $(5)^{\mathrm{a}}$ & $(5)$ & \\
Female couples & 10.6 & 6.8 & 8.7 \\
& $(5)$ & $(5)$ & \\
Cross-sex couples & 14.9 & 4.5 & 9.7 \\
& $(10)$ & $(10)$ & \\
Group Mean & 11.5 & 4.7 & \\
\hline
\end{tabular}

a Number of people appears in parentheses.

ence the same dynamics. There is a significant power-position main effect $(\mathrm{F}(1,17)=7.2$; $\mathrm{p}<$ $.02)$.

We have shown that in cross-sex couples interruptions are a function of power position, rather than sex. Since most married couples are of the traditional (male more powerful) variety (see, e.g., Blood and Wolfe, 1960; Blumstein and Schwartz, 1983), then it is obvious that husbands would generally be observed to interrupt more often. However, before we conclude that, ceteris paribus, men and women are equally likely to interrupt, we should consider the same-sex dyads. The data show that male couples produce significantly fewer successful interruptions than cross-sex or female couples (a male couple mean of 4.3 versus 9.8 for females and 9.7 for cross-sex couples; $F(2,29)=3.4 ; p<.05)$. This male pattern, however, reflects different dynamics in the power-balanced as compared to powerimbalanced couples. In the equal couples, there are few successful interruptions because there are simply few interruptions of any sort (4.2 successful out of 10.1 on average). In the power-imbalanced couples, the ratio of successful to unsuccessful interruptions is strikingly low (4.4. successful out of a total of 20.4).

Zimmerman and West (1975) reported strong sex-linked differences for overlaps as well as interruptions. Our data do not offer support for this assertion. There was no significant sex effect within the cross-sex couples (male mean of 13.7 and female mean of 12.1). We also found no effect of power position in the imbalanced couples, no matter what the sex composition. The only suggestion of any kind of sex difference occurs among the power-balanced couples, where male couples show fewer overlaps than female or cross-sex couples, which is contrary to Zimmerman and West's (1975) findings (a male couple mean of 7.2, as compared to 16.4 for female couples and $\mathbf{1 4 . 6}$ for cross-sex couples).

\section{Minimal Responses Used as a Turn}

As might be expected, male couples averaged higher rates of minimal responses than female or cross-sex couples (means of 21.2 versus 13.2 and 14.1 , respectively). The difference, however, is not significant, and in general the analyses were inconclusive, yielding no significant results. In the analysis of different power arrangements in cross-sex couples, as well as the analysis comparing more powerful and less powerful partners in the three kinds of couples, we discovered no consistent or statistically reliable patterns.

\section{Back Channels}

Table 4 shows the rates of back channels among cross-sex couples. In power-imbalanced couples, it appears that it is the less powerful person who exhibits the higher rates. A repeated-measures analysis of variance involving the imbalanced cross-sex couples yields no significant effect for sex or for the interaction of sex and position. Owing to the small number of cases involved, the position effect only approaches statistical significance $(\mathrm{F}(1,8)=2.3 ; \mathrm{p}<.16)$.

This power difference is also found in the female couples (means of 6.7 for the less powerful partner and $\mathbf{3 . 0}$ for the more powerful). However, we should note that in powerbalanced female couples there is a much higher rate of back channels (mean of 15.9). The male couples offer a very different picture from the others: the more powerful partner exhibits far more back channels than the less powerful (means of 13.9 versus 6.0).

\section{Questions and Tag Questions}

We find a consistent sex difference in question asking, with males outdistancing females. Table 5 shows the means among the cross-sex couples (sex main effect $\mathrm{F}(1,12)=10.2$; $\mathrm{p}<$ $.01)$. The sex difference also appears when we compare male and female power-imbalanced

Table 4. Mean Number of Back Channels per Quarter Hour (Cross-Sex Couples)

\begin{tabular}{lccc}
\hline & Males & Females & $\begin{array}{c}\text { Group } \\
\text { Mean }\end{array}$ \\
\hline Balanced couples & 15.6 & 11.9 & 13.7 \\
$\begin{array}{l}\text { Couples with male } \\
\text { more powerful }\end{array}$ & 5.9 & 18.1 & 12.0 \\
$\begin{array}{c}\text { Couples with female } \\
\text { more powerful }\end{array}$ & 17.1 & 2.0 & 9.5 \\
Group Mean & 12.8 & 10.6 & \\
\hline
\end{tabular}

${ }^{a} \mathrm{~N}=5$ people per cell. 
Table 5. Mean Number of Questions per Quarter Hour (Cross-Sex Couples) ${ }^{a}$

\begin{tabular}{lccc}
\hline \hline & Males & Females & $\begin{array}{c}\text { Group } \\
\text { Mean }\end{array}$ \\
\hline $\begin{array}{l}\text { Balanced couples } \\
\begin{array}{l}\text { Couples with male } \\
\text { more powerful }\end{array}\end{array}$ & 29.5 & 23.0 & 26.2 \\
$\begin{array}{l}\text { Couples with female } \\
\text { more powerful }\end{array}$ & 22.0 & 7.2 & 14.6 \\
Group Mean & 18.9 & 9.1 & 14.0 \\
\hline a N & 23.5 & 13.1 & \\
\hline
\end{tabular}

${ }^{\text {a }} \mathrm{N}=5$ people per cell.

couples (a male mean of 29.8 versus a female mean of 16.6; the cross-sex mean is 14.3 ; the sex composition main effect from analysis Type 3 is significant; $F(2,17)=7.2 ; p<.01)$.

In addition to the sex effects, position of power makes a difference in male couples and to a lesser degree in cross-sex couples. The more powerful partner in male couples asks substantially more questions (39.3 versus 20.3), and the same is true in cross-sex couples (15.6 versus 13.1). There is no difference in the female couples. The tabulation of questions did not include tag questions such as, "It's a nice day, isn't it?' These can be seen as a timid way of proffering a definition of the situation. Consistent with this characterization, we find that in cross-sex couples, the less powerful partner uses more tag questions, whether a man or a woman (see Table 6; a repeated-measures analysis of variance involving the imbalanced cross-sex couples yields a near significant power-position main effect; $F(1,8)=3.9 ; p<$ $.08)$.

There is a slight tendency among female couples for the less powerful partner to ask more tag questions. However, these couples have so few tag questions that this finding is not statistically reliable (means of 1.0 versus 0.0 ). The male couples, yet again, show a different pattern, with the more powerful partner posing many more tag questions (5.1 versus $0.0)$.

It should be noted that in each of the last

Table 6. Mean Number of Tag Questions per Quarter Hour (Cross-Sex Couples) ${ }^{a}$

\begin{tabular}{lccc}
\hline \hline & Male & Female & $\begin{array}{c}\text { Group } \\
\text { Mean }\end{array}$ \\
\hline $\begin{array}{l}\text { Balanced couples } \\
\begin{array}{l}\text { Couples with male } \\
\text { more powerful }\end{array}\end{array}$ & 1.0 & 1.7 & 1.4 \\
$\begin{array}{c}\text { Couples with female } \\
\text { more powerful }\end{array}$ & 1.3 & 2.7 & 2.0 \\
Group Mean & 3.3 & 0.3 & 1.8 \\
\hline
\end{tabular}

${ }^{a} \mathrm{~N}=5$ people per cell. three variables-back channels, questions, and tag questions-the occupant of the less powerful position among male couples averaged very low rates, although the variables were linked, according to the literature, to conversational submissiveness.

\section{DISCUSSION}

It is clear from the literature that men and women play different roles in conversation, even though there is not perfect agreement on all of the details. Men play a dominant role, controlling the interaction and frequently violating rules of polite turn taking. Women are more submissive, seeking permission to speak, and taking more responsibility for encouraging and supporting other speakers. This study was designed to "unconfound" two possible causes of these sex differences. Is it in the nature of individual men and women consistently to perform these different roles together, or is it the general power imbalance of male-female relationships which promotes different conversational responsibilities and privileges?

Our findings show that power dynamics by themselves can create a conversational division of labor parallel to the one ordinarily associated with sexual differentiation. One source of findings is couples who do not have sex as a basis for internal differentiation. We found in same-sex couples two clear areas of conversational dominance: In male couples and in female couples the more powerful partner far outdistances the other in successful interruptions. Additionally, in these couples, the more powerful partner tends to monopolize the conversation. Turning to conversational support, we found that in female couples the less powerful partner exhibits twice the rate of back channels; she also asks more tag questions.

The male couples provide exceptions when we consider two variables that have been linked to conversational support in the literature. The less powerful partner in these couples actually has lower rates of back channels and tag questions. This suggests that these men are unwilling to assume the responsibilities for conversational support. They fail to dominate the conversation and may as a consequence become alienated from the interaction. There is some evidence from the larger study that the role of the less powerful is not a comfortable one in male couples. For example, when such couples break up, it is the less powerful partner, the one who is less well educated, is less forceful and aggressive, or has a lower income, who is more inclined to want to leave (Blumstein and Schwartz, 1983:317). In conversation, the more powerful partner, 
perhaps sensing the other's alienation, compensates with the kind of supportive devices aimed at drawing him into the conversation and restoring his sense of being a valid contributor. The more powerful partner is made uncomfortable by the inequality of status in a relationship that is "supposed to be" one of status equals. At the same time he is in a superior position and therefore can do what he wants to try to restore balance. In the following example, partner 10172 is the less powerful and partner 10171 the more powerful:

Male 10172: Bill wanted to go on from there and have a pleasant evening. [It's hard to know, I mean not

Male 10171: ${ }^{[\mathrm{r}} \mathrm{Mm} \cdot \mathrm{hm}^{\mathrm{H}}$

Male 10172: knowing what the past pattern is

Male 10171: [ [Right] and everything, I mean

Male 10172: it's very hard to

Male 10171: Al just ...

$\left[\begin{array}{l}\text { to } \\ \mathrm{My}\end{array}\right]$ sense is that

Note that while the more powerful partner allows the less powerful to dominate the floor and encourages him by the use of back channels, he also chooses to interrupt and is successful in doing so. The use of back channels is a low-cost device to foster the impression of interactive equality because it clearly does not require the ceding of control. To take on a supportive role in conversation can acknowledge or endorse one's inferior identity. In a relationship between two men, the less powerful partner may reject such a symbolic acknowledgment, while the more powerful partner can take the identity upon himself as a means of restoring a feeling of parity.

Why then do we not find a similar pattern among cross-sex couples? The tenacity of traditional sex roles may be one reason for its absence in couples where the man is the more powerful. Perhaps women have not traditionally expressed sufficient alienation at their subordinate role in conversation to cause men to develop devices to draw them in and underscore their role as participants. Perhaps men have made the costs for doing so too high. Among the role-reversed couples we do not find evidence of male alienation from interaction. Indeed, in addition to high rates of back channels and tag questions, these men demonstrate their involvement with very high rates of talk. We return to the anomaly of these less powerful males below.

Another contradiction of our hypotheses can be found in the same-sex couples' use of questions. Fishman (1978) argued that women ask more questions as part of the work they do to sustain interaction. One would expect among the same-sex couples, where sex does not serve as a marker, that the less powerful partner would ask more questions. However, we find that in female couples there are no differences, and among male couples we find a pattern similar to that with back channels and tag questions, i.e., the more powerful partner exhibits higher rates. This anomaly deserves further comment, and so we will return to the issue of questions and their function in conversation.

Our findings from cross-sex couples also support the notion that power dynamics establish a conversational division of labor. Those coming from the traditional male-dominant couples cannot be used to contrast a power argument with a sex argument. However, our results from couples with equal power and from role-reversed couples (female more powerful) allow us to unconfound sex and power.

Interruptions are a critical measure of conversational dominance. In cross-sex couples, the more powerful partner, irrespective of sex, exhibits significantly higher rates. Within the couples of equal power, the rates of interruptions are virtually identical.

Another measure reflecting conversational dominance-talking time-provides only partial support for the power argument. In traditional cross-sex couples, the more powerful partner is more loquacious, but since this is the male partner, we cannot disentangle sex and power. However, when we look at the cross-sex couples of equal power, we see that males and females are very similar. These findings cast doubt on an interpretation based on sex. Turning to the role-reversed couples, the female talks more than her counterpart in traditional couples. However, the less powerful males are extremely talkative, more so than any other group in the study. These last results. support a sex argument over a power argument, unless we were to consider an idiosyncratic explanation of the extreme behavior of the less powerful men. For them, loquaciousness may be a response to role reversal. Other findings from the larger data set suggest that men are generally uncomfortable with role reversal in such realms as sexuality and income (Blumstein and Schwartz, 1983). Perhaps this discomfort takes the form of increased loquaciousness. These men may feel it necessary to call attention to themselves as participants in the interaction, and to remind their partners that it is a dialogue. It is interesting that this is the only measure where these men attempt to command the floor. By way of contrast, they tend not to interrupt their partners, and when they do they are generally unsuccessful. Interruptions are a high-risk interpersonal device, setting up the possibility of sanctions for the 
breach of polite discourse. Speakers with little power are much more likely to incur such sanctions, and so the less powerful males choose a safer route to a "conversational presence," namely, talkativeness. Indirect evidence that these men are reacting to a situation of role reversal lies in the fact that their less powerful counterparts in male couples (where there is no such thing as role reversal) are less talkative than their partners.

In the case of supportive behavior, the findings from the cross-sex couples are consistent with a power interpretation. Regardless of sex, the less powerful partner displays a higher rate of back channels and tag questions.

Taken as a whole, the findings we have just summarized go a long way toward the conclusion that it is the power dynamics of malefemale relationships which account for the division of labor in conversation. The question still remains whether there are observable sex differences over and above those attributable to relative power. Three kinds of findings can be brought to bear: sex differences among cross-sex couples of equal power; sex differences consistent with prediction from the literature found among role-reversed cross-sex couples; and differences between male couples and female couples. With respect to both conversational dominance and support, we have no sex differences in equal-power couples. Turning to role-reversed couples, we found that men are much more loquacious than women and they ask more questions. ${ }^{10}$

In comparing male and female same-sex couples, only one finding supports a sex-based prediction. Members of male couples, no matter what their power position, have higher rates of minimal responses than their counterparts in female couples. This lazy way of filling a turn seems not to be a perquisite of the more powerful person, but rather a type of male privilege. Among same-sex couples, two of our findings are the opposite of the predicted sex pattern: Among unequal couples, males are less talkative than women. Additionally, men ask notably more questions, particularly when they are in the more powerful position. ${ }^{11}$

\footnotetext{
10 Recall that this is the rate of asking questions, i.e., the number of questions standardized by the amount of talking time.

11 Interpretations based on ovreall differences between male and female couples should be made with care. While the literature might be used glibly to derive hypotheses about broad sex differences in conversational styles, it is probably safer to generalize only to patterns of differentiation within couples. For example; the literature holds that men interrupt women. On the basis of this observationeven if power were not a confounding factor-it is a large leap to the hypothesis that conversations be-
}

The findings most difficult to interpret involve the variable, questions. It is undeniably true-as Fishman (1978) argued-that one function of questions is to sustain conversation. However, it is important to take into consideration all of the other ways questions can fit into a conversational division of labor. A task leader asking for expert input is certainly a different kind of act than an expressive leader asking a participant if he or she was hurt by a criticism. In our data, questions are more common among males and among more powerful partners. This suggests that they tend to be questions which-as Bales (1950) would put it-ask for orientation, ask for an opinion, or ask for a suggestion. For example, from a female couple:

Female 4115: Was it Joyce that talked to her first?

Or from the more powerful partner in a male couple:

Male 10171: We have to come to some agreement here. What do you think?

Such patterns are not surprising, given the task focus of the conversations. Perhaps in other kinds of interactions, other kinds of questions would predominate and would be associated either with females or with the less powerful partner. Unlike some of our other measuresinterruptions, back channels, and tag questions-questions, as a conversational form, do not have a single clear-cut function. To understand a given question's function, it is therefore necessary to understand its unique meaning. There is both conceptual and methodological advantage to doing research on conversational forms. However, the issue of questions makes it clear that future studies will profit from including conversational content as well.

The content of conversation will obviously vary with the situation and the purposes that brought the actors together. Perhaps less obvious is that the form of conversation may vary similarly. If a conversation centered on the reciprocal disclosure of very intimate feelings, the division of labor might be very different from the task-oriented situation in which our couples found themselves. Power might disappear altogether as a factor and perhaps sex differences would be enormous. Future research should be directed towards systematically varying the nature of the "conversational task," as well as the type of relationship between the speakers. Dyads with a long history should be contrasted with ad hoc pairs

tween men are riddled with escalating interruptions, while women's conversations flow along, with each person politely taking her turn. 
(cf. Leik, 1963); intimate couples should be compared to more distant relationships; and multifaceted relationships, e.g., marriages, should be held up against single-purpose associations.

We measured power with several questionnaire items dealing with the partners' relative influence over decision making. These items are indirect reflections of the underlying power structure. It is our preference for a structural definition of power, seeing it as the consequence of relative dependency and deriving from the actors' differential resources and differential alternatives (Emerson, 1962). Thus it is unfortunate that we have to rely solely on the influence measures. Relative influence is a consequence of structural power, but other factors such as bargaining competence may also affect the influence process.

We have seen that power dynamics can create the conversational division of labor usually attributed to sex. We have also seen that sex by itself has very little or nothing to do with such a division of labor. We have succeeded at unconfounding sex and power. This should not, however, keep us from recognizing how closely tied they generally are among heterosexual couples (Cromwell and Olson, 1975). Understanding that power differences can create the appearance of sex differences does not reduce the realities of sexual inequality.

Some of our findings have invoked explanations based on an interaction between power and sex-for example, the anomalously talkative behavior of the men in cross-sex couples who are less powerful than their partners, and the high degree of support from the men in male couples who are more powerful than their partners. These explanations were of the form: males (or females), in a certain kind of relationship (with a male or female partner), and in a certain kind of power position (higher, equal, or lower) behave in a manner that could not be predicted by sex, power, or type of relationship alone. There is therefore clear explanatory utility to the concept of sex, but only when key structural conditions are considered. Men are different from women. Structural properties of their relationship will often affect them similarly, but some combinations of properties will produce unique outcomes. Without consideration of those structural effects, sex, as a quality of persons, appears to be a concept of limited utility in understanding the nature of conversation.

\section{REFERENCES}

Argyle, Michael, Mansur Lalljee and Mark Cook

1968 "The effects of visibility on interaction in a dyad." Human Relations 21:3-17.
Bales, Robert F.

1950 Interaction Process Analysis: A Method for the Study of Small Groups. Cambridge, MA: Addison-Wesley.

Bell, Alan P.

1974 "Homosexualities: Their range and character." Pp. 1-26 in 1973 Nebraska Symposium on Motivation. Lincoln: University of Nebraska Press.

Bell, Alan P., Martin S. Weinberg and Sue Kiefer Hammersmith

1981 Sexual Preference: Its Development in Men and Women. Bloomington: Indiana University Press.

Bernard, Jessie

1972 The Sex Game. New York: Atheneum.

Blood, R. O. and D. M. Wolfe

1960 Husbands and Wives: The Dynamics of Married Living. New York: Free Press.

Blumstein, Philip and Pepper Schwartz

1983 American Couples: Money, Work, Sex. New York: William Morrow.

Courtright, John A., Frank E. Millar and L. Edna Rogers-Millar

1979 "Domineeringness and dominance: replication and expansion." Communication Monographs 46:179-92.

Cromwell, Ronald E. and David H. Olson (eds.)

1975 Power in Families. New York: Wiley.

Dubois, Betty Lou and Isabel Crouch

1975 "The question of tag questions in women's speech: They don't really use more of them, do they?" Language in Society 4:289-94.

Eakins, Barbara W. and R. Gene Eakins

1978 Sex Differences in Human Communication. Boston: Houghton Mifflin.

Emerson, Richard M.

1962 "Power-dependence relations." American Sociological Review 27:31-41.

Fishman, Pamela M.

1978 "Interaction: the work women do." Social Problems 25:397-406.

1980 "Conversational insecurity." Pp. 127-32 in Howard Giles, W. Peter Robinson and Philip M. Smith (eds.), Language: Social Psychological Perspectives. New York: Pergamon Press.

Gagnon, John H. and William Simon

1973 Sexual Conduct: The Social Sources of Human Sexuality. Chicago: Aldine.

Hilpert, Fred, Cheris Kramer and Ruth Ann Clark

1975 "Participants' perception of self and partner in mixed-sex dyads."' Central States Speech Journal 26:52-56.

Kramer, Cheris

1974 "Women's speech: separate but unequal?" Quarterly Journal of Speech 60:14-24.

\section{Lakoff, Robin}

1975 Language and Woman's Place. New York: Harper \& Row.

Lapadat, Judy and Maureen Seesahai

1977 "Male versus female codes in informal contexts." Sociolinguistics Newsletter 8: 7-8.

Leik, Robert

1963 "Instrumentality and emotionality in family interaction." Sociometry 26:131-45. 
Marlatt, G. A.

1970 "A comparison of vicarious and direct reinforcement control of verbal behavior in an interview setting." Journal of Personality and Social Psychology 16:695-703.

Natale, Michael, Elliot Entin and Joseph Jaffe

1979 "Vocal interruptions in dyadic communication as a function of speech and social anxiety." Journal of Personality and Social Psychology 37:865-78.

Octigan, Mary and Sharon Niederman

1979 "Male dominance in conversations." Frontiers 4:50-54.

Parks, Malcom R.

1978 "Perceived sex differences in friendship development." Paper presented at the annual convention of the Speech Communication Association.

Raush, Harold L., William A. Barry, Richard K. Hertel and Mary Ann Swain

1974 Communication Conflict and Marriage. San Francisco: Jossey-Bass.

Rogers, William T. and Stanley E. Jones

1975 "Effects of dominance tendencies on floor holding and interruption behavior in dyadic interaction." Communication Research 1:113-22.

Rosenfeld, Howard M.

1966 "Approval-seeking and approval-inducing functions of verbal and nonverbal responses in the dyad." Journal of Personality and Social Psychology 4:597-605.

Sacks, Harvey, Emanuel Schegloff and Gail Jefferson

1974 "A simplest systematics for the organization of turn-taking for conversation." Language 50:696-735.

Schegloff, Emanuel

1972 "Sequencing in conversational openings." Pp. 346-80 in John Gumperz and Dell Hymes (eds.), Directions in Sociolinguistics: The Ethnography of Communications. New York: Holt, Rinehart \& Winston.
Soskin, William F. and Vera P. John

1963. "The study of spontaneous talk." Pp. 228-81 in Roger Barker (ed.), The Stream of Behavior. New York: AppletonCentury-Crofts.

Strodtbeck, Fred L.

1951 "Husband-wife interaction over revealed differences." American Sociological Review 16:468-73.

Swacker, Marjorie

1975 "The sex of the speaker as a sociolinguistic variable." Pp. 76-83 in Barrie Thorne and Nancy Henley (eds.), Language and Sex: Difference and Dominance. Rowley, MA: Newbury House.

Symons, Donald

1979 The Evolution of Human Sexuality. New York: Oxford University Press.

Thorne, Barrie and Nancy Henley (eds.)

1975 Language and Sex: Difference and Dominance. Rowley, MA: Newbury House.

Thorne, Barrie, Cheris Kramer and Nancy Henley (eds.)

1983 Language, Gender and Society. Rowley, MA: Newbury House.

Weinberg, Martin S.

1970 "Homosexual samples: differences and similarities." Journal of Sex Research 6:312-25.

West, Candace

1984 "When the doctor is a 'lady': power, status and gender in physician-patient encounters." Symbolic Interaction 7:87-106.

West, Candace and Don H. Zimmerman

1977 "Women's place in everyday talk: reflections on parent-child interactions." Social Problems 24:521-28.

Zimmerman, Don H. and Candace West

1975 "Sex roles, interruptions and silences in conversation." Pp. 105-29 in Barrie Thorne and Nancy Henley (eds.), Language and Sex: Difference and Dominance. Rowley, MA: Newbury House. 